\title{
Investigation of route choice behaviour in passenger transport
}

\author{
Adam TOROK*, Ferenc MESZAROS* \\ *Budapest University of Technology and Economics, Budapest, Hungary \\ atorok@kgazd.bme.hu, fmeszaros@kgazd.bme.hu
}

\begin{abstract}
The continually increasing population, the rising economic activity and the permanent race for the rise of economic prosperity, led us to the increase of motorisation. Transportation sector has an important role, because it is not only using the lacking fossil energy sources and polluting the environment, but because of our social and economic structure it is the sector that can hardly change because of the big social resistance. One of the substantial preconditions for the change into an environmental friendly, sustainable system is correct data provision to the regulator (quality and quantity as well). One way for reduction of transport related environmental pollution is to give right price signal to the users with internalisation of transport related external costs. In our article we tried to examine the route choice behaviour in Hungary focusing on toll roads. Our aim in this paper is to analyze the correlation of control possibilities of such econometric phenomena with mathematic tools.
\end{abstract}

\section{INTRODUCTION}

One of the most striking characteristics of the 20th century was the emergence of the automobile for passenger transportation. There are over 700 million of these vehicles in circulation today around the world, the great majority of them with Otto cycle engines running on gasoline. Automobiles are an integral part of everyday life of developed society. They shaped the whole transportation system of mankind and represent a very significant fraction of the GDP of many countries. As developing countries grow and expand, the number of automobiles in the world will increase [1]. The number of vehicles per capita is filling up in industrialized countries, but is much smaller in today's developing countries. In China there are only 20 automobiles per 1000 people compared to 700 per 1000 people in the United States of America. In Hungary we had 300 passenger cars for 1000 people in 2006.

The consumption of gasoline necessary to run these automobiles is roughly 20 million barrels of crude oil equivalent per day, one quarter of the world petroleum consumption from which it is produced and, unfortunately, petroleum is found in relatively few regions of the world. Exports and imports of this commodity are the most important items in international trade, and many countries are critically dependent on petroleum imports.

The current mobility behaviour of population is in need of change towards a sustainable transportation system with better utilisation of alternatives. This leads to lower dependency on fossil fuels and reduced harmful emission.
Our aim was to analyze the application of road toll measure and the control possibilities of travellers in route and transportation mode choice with elasticity calculations, furthermore to model the modal and route choice as human behaviour.

\section{SITUATION OF THEORETICAL INVESTIGATION}

Let us assume that there are two different routes (as a part of a graph) on the road network. One with high capacity and high service level offered (interurban expressway), another one with low capacity and low service level (trunk road crossing cities and towns) - see Fig. 1. Basic situation is that both routes are free of charge for the users. First we introduce a standard toll system (vignette system for example - taking into consideration on the wear and tear costs) on the road with high capacity and service level. Consumer responses to changes in mobility prices are often measured by elasticity. When the price of road transportation has been changed, the utility function of travellers consequently has been also changed. Higher transport prices affect demand for transport through two main channels. At first, consumers respond by changing their route and secondly, they change their mode of mobility. In our case those people who need to reach the destination in limited time period, has a higher value of (travel) time will pay the toll [2]. Those who want to reach the destination with small expenses will choose the road with lower capacity and lower service level, free from any tolls.

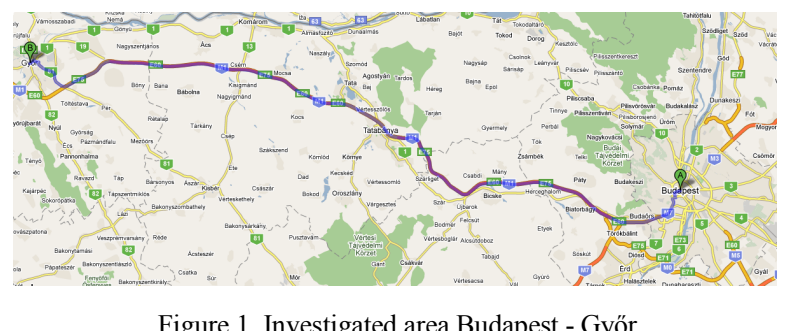

Figure 1. Investigated area Budapest - Győr (source: www.googlemaps.com)

In macroeconomical sense we modelled the decision about route choice. We tried to build up a model based on utility functions and analyze the results. Practical uses of supply and demand analysis often centre on the different variables that change equilibrium price and quantity, represented as shifts in the respective curves (Fig 2.). In the literature both affine and nonlinear approximations of the demand and supply curves are in use. The Authors of 
the present paper apply affine approximation for this purpose that used to be reasonable within more or less narrow intervals. Comparative static of such a shift traces the effects from the initial equilibrium to the new equilibrium.

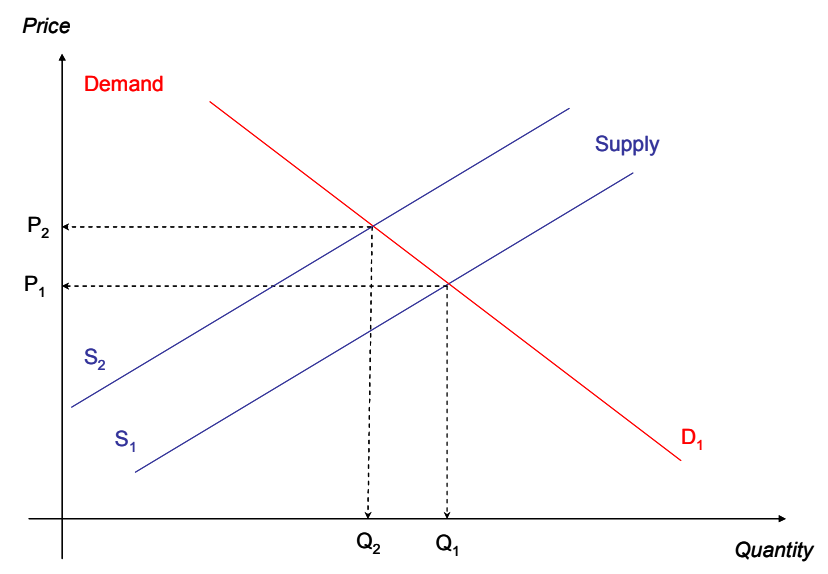

Figure 2. Change of supply curve [3]

We had an unwanted left-ward shift in supply that decreased quantity. With increasing of road toll the traffic is decreasing so even higher service level has been reached. Due to the increased paying obligations, less people want to travel on the higher service level road and part of the traffic is diverted to the free of charge route. In the diagram, this increases the equilibrium price from $P_{1}$ to the higher $P_{2}$ and lower the traffic from the $Q_{1}$ to the $Q_{2}$ value. The lower service level road runs through cities and towns. The increased traffic volume on lower service level road causes substantial damage in the infrastructure and environment to the cities and citizens. To lower the caused damage with social cost, the traffic volume is in need to be lowered. For this reason, a diverse distance based tolling should be introduced also on this road, internalizing of externalities with focusing on the polluter pays principle, to ensure that the diverted traffic turns back to the high service level road. After introducing the distance based toll regimes on both routes, the road transportation becomes more expensive, so some people will shift to public transportation modes, so traffic volume on the road will be less. Mathematically the demand function can be described as:

$\mathrm{x}_{\mathrm{t}}=\mathrm{a}_{\mathrm{t}} \cdot \mathrm{p}_{\mathrm{t}}+\alpha_{\mathrm{t}}$

, as demand function where

$\mathrm{x}_{\mathrm{t}}$ : the demand for the road

$\mathrm{p}_{\mathrm{t}}$ : price in time $\mathrm{t}$

t: time period

$a_{t}<0$ and $\alpha_{t}>0$, these parameters are determined by tools of econometry

In the example above, there has been a decrease in demand which has caused a decrease in (equilibrium) quantity. If we take into consideration that the roads behaving like concurring products, and the decrease of demand for one will increase the demand for the other only if the other circumstances remain constant. Mathematically the supply function can be described as $\mathrm{y}_{\mathrm{t}}=\beta_{\mathrm{t}}+\mathrm{b}_{\mathrm{t}} \cdot \mathrm{p}_{\mathrm{t}-1}$

, as supply function where

$\mathrm{y}_{\mathrm{t}}$ : the supply of road

$\mathrm{t}-1$ : time period before time period $\mathrm{t}$

$b_{t}>0$ and $\beta_{t}<0$, these parameters are determined by tools of econometry

It is well known that market equilibrium is when demand $\mathrm{x}_{\mathrm{t}}$ and supply $\mathrm{y}_{\mathrm{t}}$ are equal. For every time period $\mathrm{t}$ there is an equilibrium that can be described with

$a_{t} \cdot p_{t}+\alpha_{t}=b_{t} \cdot p_{t-1}+\beta_{t}$
$a_{t} \cdot p_{t}=b_{t} \cdot p_{t-1}+(\beta-\alpha)_{t}$

We reach the final market equilibrium when $\mathrm{p}_{\mathrm{t}}=\mathrm{p}_{\mathrm{t}-1}$. Therefore, we get

$\hat{p}_{t}=\left(\frac{\beta-\alpha}{a-b}\right)_{t}$

where

$\hat{\mathrm{p}}_{\mathrm{t}}$ : final market equilibrium price

On this basis Eq.(4) is the determination of the equilibrium at which the demand exactly meets the supply. The actual price differs from the market equilibrium price with

$\widetilde{p}_{t}=p_{t}-\hat{p}=p_{t}-\left(\frac{\beta-\alpha}{a-b}\right)_{t}$

where

$\widetilde{\mathrm{p}}_{\mathrm{t}}$ : difference between price in time $\mathrm{t}$ and final market equilibrium

At this time the market equilibrium can be described as:

$$
\begin{aligned}
& a_{t} \cdot \widetilde{p}_{t}=b_{t} \cdot \widetilde{p}_{t-1} \\
& \widetilde{p}_{t}=\left(\frac{b}{a}\right)_{t} \cdot \widetilde{p}_{t-1}
\end{aligned}
$$

where

$\tilde{\mathrm{p}}_{\mathrm{t}-1}$ : difference between price in time period before time period $t$ and final market equilibrium 


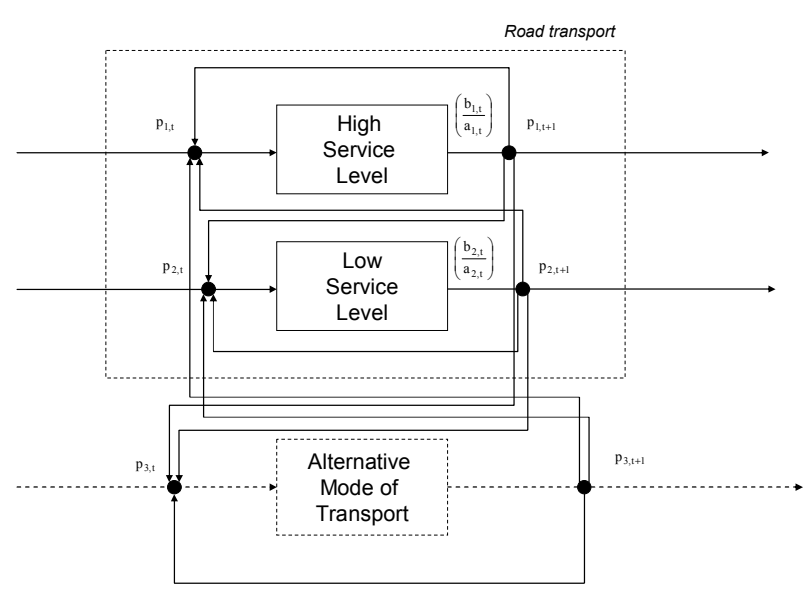

Figure 3. Cybernetic model of market equilibrium with concurring products [4]

With the above mentioned model (Figure 3.) we tried to analyze the effects of concurring routes and modes in Hungary. The meaning of the fat dots in the figure above is connection point of loops to the input. Because the outs have effect on inputs.

\section{RESULTS}

As a consequence of the explosive growth of the volume of the vehicle traffic the analysis of the demand of the vehicular traffic becomes more and more important. The traffic characteristics of an existing transport relation are being shaped during years [5]. The topic of this point is the revealing analysis of the vehicular relations connecting Budapest and Gyor, building on the traffic data for year 2006. For the internalisation of externalities - at least the environmental part - this reason we divided the vehicle fleet by environmental categories (EURO1 and below, EURO2, EURO3, EURO4, and EURO5 and better) and we categorized them according to cylinder capacity (up to $1399 \mathrm{~cm}^{3}, 1400-1999 \mathrm{~cm}^{3}$, from $2000 \mathrm{~cm}^{3}$ - Fig 4). The aim of the group formation is the estimate of the complex environment pollution.

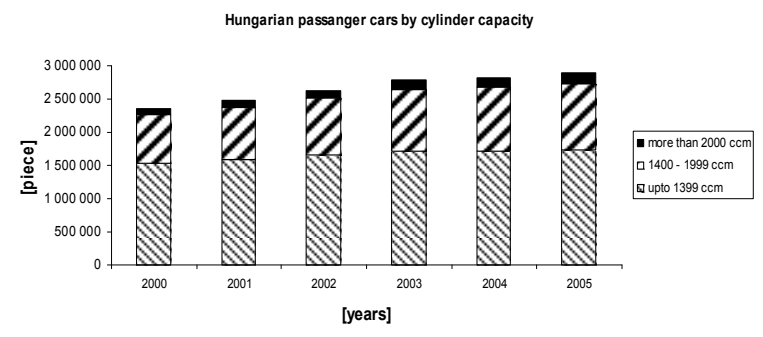

Figure. 4. Hungarian passenger cars by cylinder capacity (source: Hungarian Central Statistical Office, own research)

On the basis of the above categorization we simulated the vehicle flow of the two routes: M1 motorway (high service level) and trunk road no. 1 (lower service level) according to cylinder capacity and environmental standard grouping.

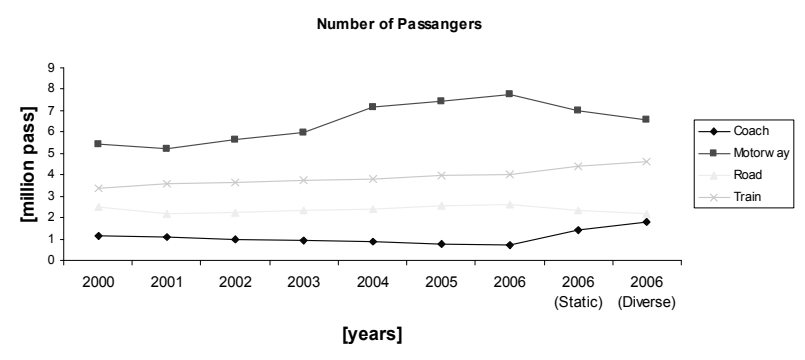

Figure 5. Simulation of different toll strategies (source: own research)

After simulating the expected value of the vehicle flow we separated three cases. In the first case nothing changed. In the second case we added constant level tolls to the vehicle flow on the M1 motorway and trunk road no. 1, therefore in 2006 static case the passenger flow of train and bus will increase and the passenger flow of road and motorway will decrease. In the third case we examined the set of the traffic and added a diverse tolling measure formed by the complex environmental groups, taking into account the cylinder capacity and EURO classification of vehicles, therefore in 2006 diverse case the passenger flow of motorway and road decreased and the passenger flow of train and bus will decrease

The results of the traffic model calculations are summarized and demonstrated in Figure 5.

\section{CONCLUSION}

From the point of view of economics the main assumptions of the paper are based on Marshall's fundamental model [Alfred Marshall: Principles of Economics (1890)]. According to his model it is assumed that the operation of the economy is determined by the "equilibrium point", that is at the price at which the supply is equal to the demand. This paper consist in the application of Marshall's principles in a particular field, that is in the control of road traffic by properly manipulating the fees to be paid by the various participants of the traffic driving various vehicles grouped according to the environmental categories. Motorisation causes perceptible environmental externalities. The locally effective emission that has been taken into account by the EURO environmental categories, and the globally effective one which has been taken into account by the piston displacement. In the course of our experiments we revealed that the standard use of road tolling regime enhances the usage of the roadsystem offering inferior, lower service standards, but this diversion leads lower comfort feeling of citizens living in the neighbourhood. Furthermore, our experiments prove that the present tax- and standard toll-system is coherent (anyway with the current tolling legislation) neither with the EU's traffic- and environmental policy, nor with the present governing principles of the European Union. Reducing greenhouse gas emission will cost money from the states and the society, but the amounts required are clearly affordable. It is important to remember that climate policies can bring many win-win benefits. Reforming and diversification of pricing systems will have to be one of the international community's top priorities over the coming decades to reach the desirable 
sustainability. There will be many difficulties and detour along the road to build climate friendly economies.

\section{V.ACKNOWLEDGEMENT}

The authors gratefully acknowledge to the support by the Hungarian National Scientific Research Fund (OTKA CNK 78168).

\section{REFERENCE}

[1] Katalin TÁNCZOS, Ádám TÖRÖK: Impact of transportation on environment, Periodica Polytechnika Transportation Engineering, 2008, p105-110.

[2] Dániel VÁRKONYI, Máté ZÖLDY, Ádám TÖRÖK (2008): Road pricing and climate change at IV. TEN-T corridor in Hungary, TRAVEL DEMAND MANAGEMENT CONFERENCE, 16 June 2008

[3] Oscar R. LANGE: Intorduction of economic cibernetics (in Hungarian), Közgazdasági és Jogi Könyvkiadó, Budapest, 1967, p237

[4] Zoltan PETRES, Adam TOROK: Analysis of biofuel based mobility in hungary., $10^{\text {th }}$ European Conference of International Association for Energy Economics, 2009, p174-175., ISSN 1559 792X

[5] Eva GILICZE, et al.: Mathematical tools and models in transportation - (in Hungarian), Tankönyvkiadó, Budapest, 1971, p185 